\title{
DEPÓSITOS DO PLEISTOCÉNICO SUPERIOR E DO HOLOCÉNICO NA PLATAFORMA LITORAL DA REGIÃO DO PORTO: A MORFOLOGIA DAS PLATAFORMAS DE EROSÃO MARINHA E A TECTÓNICA RECENTE
}

\author{
MARIA DA ASSUnÇão ARAÚJO*
}

Resumo

Abstract

\begin{abstract}
Apresentamos o estudo de depósitos do litoral da região do Porto, incluindo datações por termoluminescência, bem como o pormenorizado levantamento topográfico geo-referenciado por GPS de precisão. O principal objectivo deste trabalho visou identificar distintas plataformas de erosão marinha, definindo a altimetria da plataforma actual, de uma plataforma intermédia, presumivelmente, flandriana, bem como da plataforma correspondente ao último interglaciar (Eemiano), o que é atestado pelos depósitos que conserva. $\mathrm{O}$ estudo permitiu confirmar as hipóteses de uma variação altimétrica apreciável nos depósitos correspondentes ao último interglaciar, atribuíveis à neotectónica.
\end{abstract}

Palavras-chave: plataforma litoral, depósitos marinhos, datações por TL, georeferenciação de precisão, Eemiano, Flandriano, neotectónica.

\begin{abstract}
Upper Pleistocene and Holocene deposits in the coastal platform of the Porto region: the morphology of the marine platforms and neotectonics: the study of Quaternary sedimentary deposits of the coastal zone of Porto included a very detailed fieldwork and the accurate altitude definition with a GPS (Leica SR20). Luminescence dating of aeolian and lagoon deposits was performed to confirm our hypothesis about the deposits chronology and recent tectonic movements. However, the marine deposits can not be dated by TL and even OSL is quite problematic due to the small thickness of the beds. Our main goal is to characterize the several marine platforms along this coastline. It was possible to identify the present-day marine platform, some rare tiny Flandrian platform remains and also the more frequent and generally deposit bearing Eemien platform. This work has proved that even the last interglacial marine deposits have suffered some tectonic disturbance as they appear at quite different altitudes along this coastal zone.
\end{abstract}

Key-words: littoral platform, marine deposits, OSL, precision GPS, Eemien, Flandrian, neotectonics.

\section{INTRODUÇão}

Este trabalho visa apresentar novas interpretações sobre a plataforma litoral da região do Porto com base em trabalhos anteriores da autora (ARAÚJo 1991, 1997, 2000, 2001; ARAÚJO et al., 2003) e no resultado de novas pesquisas recentemente desenvolvidas, nomeadamente num trabalho de campo muito pormenorizado, apoiado num sistema de GPS com correcção diferencial.

\section{ENQUADRAMENTO GEOLÓGICO}

Os conhecimentos sobre a geologia desta região têm vindo a ser enriquecidos pelos trabalhos de diversos investigadores (CHAMINÉ, 2000; NORONHA \& LETERRIER, 2000; CHAMINÉ et al., 2003), de que apresentamos uma breve síntese.

A faixa litoral entre Vila do Conde e Espinho compreende duas zonas tectónicas do Maciço Hespérico: Zona Centro Ibérica (ZCI) e zona OssaMorena (ZOM) (Fig. 1).
A ZCI corresponde à parte central do orógeno ibérico (RIBEIRO et al., 1979). Predominam rochas do Complexo Xisto-grauváquico ante-ordovícico (CXG), tidas como do Câmbrico (idem, ibidem) e diferentes tipos de granitos. Dum modo geral, os xistos do CXG correspondem a alternâncias monótonas de filitos e metagrauvaques. As formações posteriores ao CXG aparecem no anticlinório de Valongo, com um desenvolvimento oblíquo relativamente à linha de costa que só atingem na região de Ofir.

$\mathrm{O}$ processo de granitização correspondente à formação de granitos alcalinos produziu um intenso metamorfismo que pode ser apreciado na orla costeira, onde as rochas estão polidas pela acção da erosão marinha (TEIXEIRA, 1968). Por sua vez, os granitos calco-alcalinos de Lavadores intruíram ao longo da descontinuidade existente entre ZCI e a ZOM, constituindo uma faixa de direcção NNWSSE que aflora junto à costa, na praia de Lavadores, inflectindo depois para o interior.

\footnotetext{
* Departamento de Geografia, Faculdade de Letras da Universidade do Porto. E-mail: m.a.araujo@netcabo.pt
} 


\section{Esboço Geológico da Faixa litoral entre a Póvoa de Varzim e Ovar}

(Adaptado de Oliveira et al. 1992, Noronha 1994, Chaminé 2000, Chaminé et al. 2003)

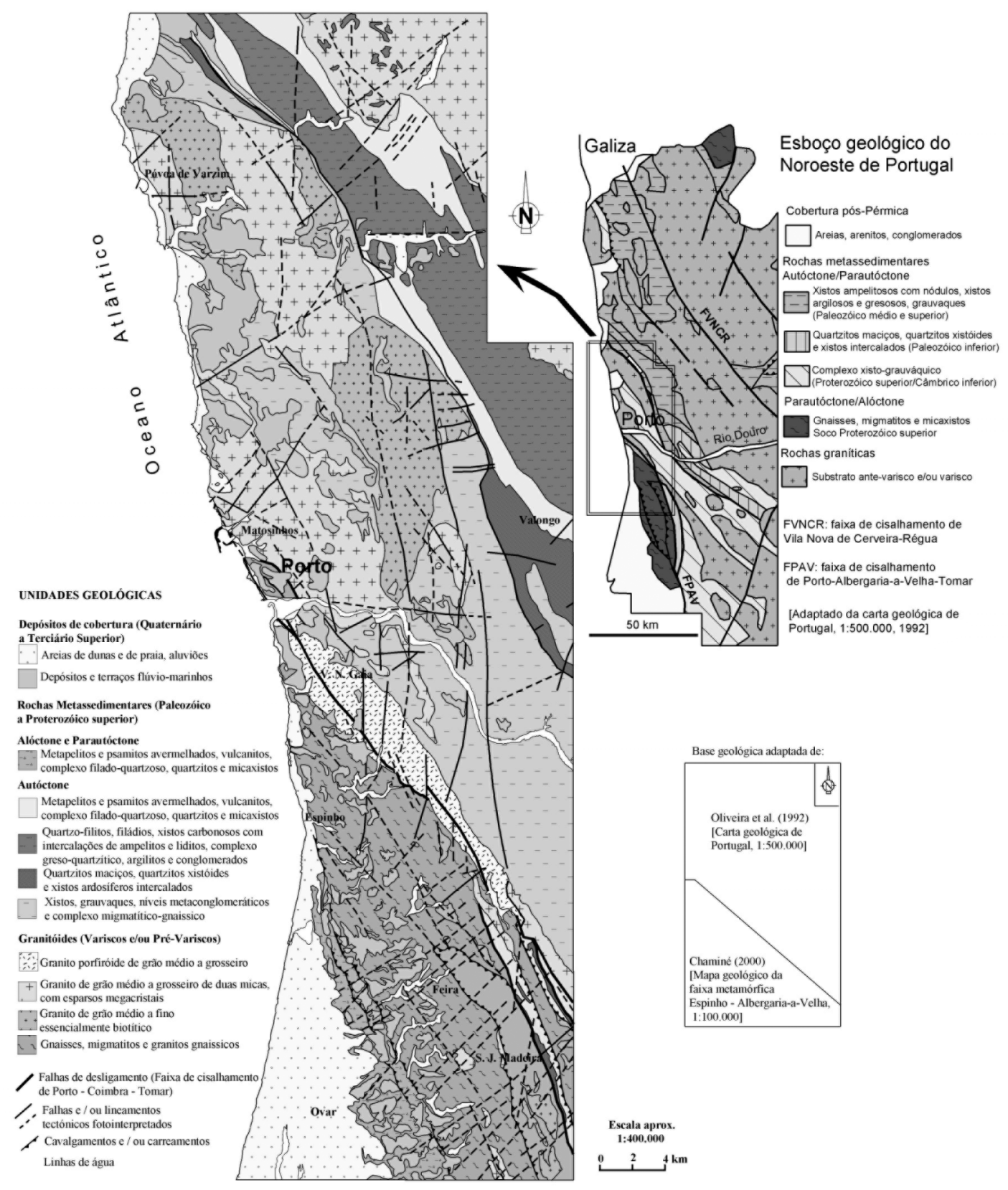

Fig. 1 - Enquadramento geológico.

Fig. 1 - Geological map. 
Segundo Borges et al. (1985), o granito do Castelo do Queijo pertence também ao conjunto dos granitos calco-alcalinos, mais recentes que o granito alcalino, de duas micas, designado como granito do Porto.

$\mathrm{Na}$ área da Foz do Douro e a partir da latitude de Lavadores até Espinho, o litoral corresponde a uma faixa metamórfica, de direcção geral NNW-SSE que se inclui na Zona de Ossa-Morena (NORONHA \& LeTERRIER, 2000; CHAMINÉ, 2000; CHAMINÉ et al., 2003). Para mais informação ver Araújo et al. (2003) e Chaminé et al. (2004). Trata-se de uma faixa em que o grau de metamorfismo vai diminuindo no sentido SW, aparecendo migmatitos e gnaisses na praia da Madalena e xistos metamórficos mais a sul. Estas últimas rochas apresentam uma menor resistência à erosão mecânica, o que poderá explicar, em parte, a extensão da plataforma de erosão marinha que se pode apreciar entre as praias da Aguda e da Granja, um dos sectores chave que pretendemos abordar neste trabalho.

\section{A COBERTURA CENOZÓICA}

Sobre as rochas pré-câmbricas e paleozóicas que se encontram na plataforma litoral, existem muitos retalhos de depósitos do Cenozóico (ARAÚJO, 1997, 2000).

Em Araújo et al. (2003) encontra-se uma síntese da evolução desta zona costeira durante o Cenozóico para a qual se remete o leitor. O MDT (modelo digital de terreno) da figura 2 representa a localização dos pontos referidos no texto.

Os elementos mais antigos da cobertura cenozóica aparecem geralmente na imediata proximidade do "relevo marginal" (ARAÚJO, 1991) e é nossa convicção que se terão formado antes da movimentação que terá dado origem àquele relevo, que funcionaria como um horst que separa a plataforma litoral das áreas interiores (ARAÚJO, 2000). Cabral \& Ribeiro (1989) registam a existência de duas escarpas de falha coincidentes com a localização do relevo marginal nesta área. Infelizmente, a representação destas falhas é algo confusa, sugerindo a existência de uma escadaria tectónica descendo para Oeste, em clara contradição com a topografia. Poderá, eventualmente, tratar-se de um erro de impressão devido à pequena escala do mapa (1:1.000.000).

Desde o topo da plataforma litoral, que se inicia a cerca de $125 \mathrm{~m}$ na área a sul do Rio Douro, até altitudes de cerca de $50 \mathrm{~m}$ no extremo Sul da região estudada, todos os depósitos encontrados apresentam fácies continentais. Os depósitos inequivocamente marinhos, apresentam-se em manchas de dimensões geralmente inferiores às dos depósitos fluviais e a altitudes inferiores a $40 \mathrm{~m}$.

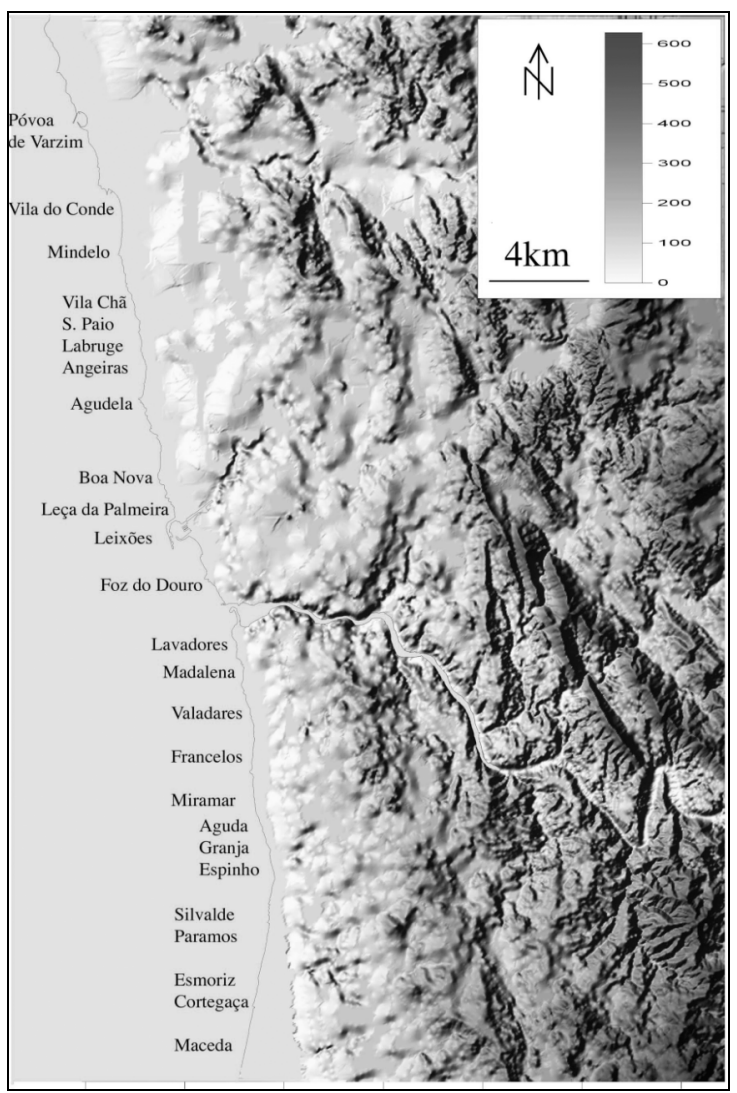

Fig. 2 - Morfologia regional e localização das praias referidas no texto.

Fig. 2 - Regional geomorphology and beaches localization.

Embora a cobertura cenozóica seja pouco espessa e descontínua, foi possível identificar depósitos que podem ser organizados em três conjuntos que testemunham sucessivas fases evolutivas (ARAÚJO, 1991):

- fase I: depósitos mais altos, culminando a cerca de $125 \mathrm{~m}$ na área considerada, com sedimentos geralmente bem calibrados. Este conjunto corresponde aos depósitos mais antigos. Por comparação com os depósitos da Bacia de Mirandela, admite-se para estes uma idade placenciana provável (PEREIRA et al., 2000);

- fase II: depósitos de uma faixa intermédia, a altitudes entre $100 \mathrm{~m}$ e $42 \mathrm{~m}$. São depósitos de tipo leque aluvial, com sedimentos muito mal calibrados. Por terem sido gerados após os depósitos da fase I, do provável Placenciano $(3,6$ Ma a 2,4 Ma) e anteriormente aos depósitos claramente quaternários, admite-se uma idade do Gelasiano (2,4 Ma a 1,8 Ma) ou Pleistocénico inicial; 
- fase III: depósitos marinhos que aparecem abaixo dos $40 \mathrm{~m}$. Estão separados dos anteriores por um degrau rectilíneo que sugere um abatimento da parte ocidental da plataforma litoral segundo uma direcção grosseiramente meridiana (ARAÚJO, 2000). O compartimento abatido seria depois retocado por acção marinha que reutilizaria alguns dos depósitos fluviais tectonicamente abatidos e situados numa posição que os deixou ao alcance da acção erosiva do mar. Esse sector tectonicamente abatido vai ser sujeito às oscilações glacio-eustáticas que nele vão imprimir uma escadaria de depósitos de origem marinha.

\section{O ESCALONAMENTO DOS DEPÓSITOS MARINHOS}

Os estudos efectuados identificaram na Fase III a existência de, pelo menos, três "níveis" de depósitos marinhos, que designámos, por ordem cronológica, do mais antigo para os mais recentes, como níveis 1,2 e 3.

Estes "níveis" foram definidos, essencialmente, através de critérios sedimentológicos (ARAúJO, 1991), já que, como se verá, a posição altimétrica em cada um deles pode variar localmente. Por isso, o uso da designação de "níveis" não representa uma adesão às teorias fixistas do eustatismo, mas apenas o facto de os depósitos marinhos se apresentarem escalonados em cada sector considerado e, deste modo, poderem ligar-se a diferentes episódicos genéticos. Infelizmente, é raro encontrar num mesmo local todos estes "níveis" de depósitos preservados e bem expostos. $\mathrm{O}$ único local onde foi possível definir os três "níveis" propostos foi na área de Lavadores (Canidelo, Vila Nova de Gaia), onde se apresentam formando uma escadaria. Por isso, as altitudes indicadas para cada "nível" são aquelas que correspondem à altitude em que o mesmo se encontra na área de Lavadores.

Os depósitos que se apresentam em manchas mais extensas são, normalmente, aqueles que se situam ao longo da já referida fractura meridiana, imediatamente a Oeste dos depósitos fluviais e a altitudes compreendidas entre $28 \mathrm{~m}$ e $37 \mathrm{~m}$. Estes depósitos compreendem ao "nível 1". Trata-se de afloramentos razoavelmente espessos (1-2 m) que assentam sobre um substrato rubefacto bastante alterado.

Os depósitos do "nível 2" apresentam alguma ferruginização (cor acastanhada), assentam sobre um substrato cuja alteração, menos intensa do que a do nível precedente, lhes confere uma cor esbranquiçada, e situam-se a 18-15 m de altitude.

Os depósitos do "nível 3" aparecem a altitudes inferiores a $10 \mathrm{~m}$, e em certos locais situam-se ao nível médio actual das marés altas, como sucede entre as praias da Aguda e da Granja. Apresentam cor castanha, correspondente a uma ferruginização bastante intensa que, por vezes, os litificou. Este depósito, fortemente encouraçado, aflora, por exemplo, na praia da Circunvalação, um pouco a norte do "Edifício Transparente". O substrato rochoso dos depósitos do nível 3 apresenta apenas uma alteração incipiente e uma pâtine castanha ou alaranjada, contemporânea da cimentação do depósito suprajacente.

O estudo do escalonamento dos depósitos marinhos baseado nas características acima referidas permitiu concluir que os depósitos atribuíveis a um mesmo "nível" não se situam sempre à mesma altitude. Desenvolvem-se segundo um padrão algo irregular (ARAÚJO, 1997), conforme figura 4, que sugere a existência de movimentos tectónicos verticais com componente transversal ou oblíqua em relação à linha de costa (ARAÚJO, 1991, 1997).

\section{DifiCuldades de dataÇão E O USO de NOVAS METODOLOGIAS}

A margem ocidental ibérica tem sido definida como uma margem continental passiva, portanto, com uma tectónica pouco activa. Por isso, temos consciência de que a proposta de movimentações tectónicas afectando depósitos recentes (por ex. do último interglaciar) necessita de confirmação.

Os trabalhos de Ribeiro (1984), Cabral \& Ribeiro (1989) e Ribeiro (2002) têm vindo a modificar a visão clássica da tectónica da margem ocidental ibérica. Porém, para aplicar as concepções mobilistas à situação em análise, torna-se necessário confirmar a contemporaneidade de alguns depósitos situados a altitudes diversas, até agora baseada nas suas semelhanças em termos sedimentológicos, através de datações absolutas ou paleontológicas, ou pelo seu posicionamento morfológico, de forma a dar mais consistência às hipóteses apresentadas.

Dado que os depósitos mais baixos (nível 3 da fase III), acima definidos, são, naturalmente, aqueles que apresentam aforamentos mais frequentes e mais bem conservados, será sobre estes depósitos, presumivelmente eemianos, que vai incidir a nossa análise.

A nossa primeira tentativa para datar os depósitos por TL foi efectuada com recurso a uma prestação de serviço efectuada por Nick Debenham (Quaternary TL Surveys) em Agosto de 2003, em que se visitaram os afloramentos mais representativos. Infelizmente, dado que a TL apenas usa grãos muito finos $(4-10 \mu \mathrm{m})$ na medição de luminescência, só foi possível amostrar um depósito eólico e outro lagunar, mas não os depósitos marinhos que eram o nosso principal objectivo. Os resultados das referidas datações serão referidos mais à frente neste trabalho. 
Além de apresentarem custos elevados, as análises por TL ou OSL são tecnicamente muito complexas e os seus resultados comportam algumas incertezas (WALlinga, 2002). Devido ao facto de existir uma radioactividade elevada, fruto do substrato granítico de uma boa parte do país ou de uma significativa matriz argilosa (MARTINS \& CunHA, 2006a e 2006b), os grãos de quartzo (em OSL) ou uma mistura polimineral (em TL), utilizados como dosímetro, encontram-se geralmente saturados e as respectivas datações não podem realizar-se para além de idades relativamente recentes. Para tentar obviar ao problema, existe a moderna técnica da datação OSL em grãos detríticos de feldspato $\mathrm{K}$, mas esta apresenta uma maior complexidade devido à necessidade de corrigir o "anomalous fading" (MARTINS \& CUNHA, 2006b), sendo muito raros os laboratórios que executam esta metodologia.

Devemos ainda referir um outro problema. Para as datações por luminescência não devem ser amostrados arenitos cimentados por óxidos de ferro (A. MARTINS, comunicação oral). Ora, aquilo que contribui para a conservação dos depósitos do Eemiano que se encontram nesta área, é, justamente, a sua cimentação por óxidos de ferro. Significa isso que mesmo que seja possível, por datação OSL de quartzo, alcançar idades precisas da ordem dos 125 mil anos (o que só resultaria com uma dose de radiação natural do sedimento bastante baixa ou com recurso à datação de feldspato $\mathrm{K}$ ), a cimentação das areias, como vimos acima a propósito da praia da Circunvalação, iria dificultar fortemente quer o processo de amostragem quer a obtenção de resultados fiáveis, por ser provável que tenha existido, no perfil, migração de isótopos radioactivos.

\section{O TRABALHO DE GEO-REFERENCIAÇÃO DOS DEPÓSITOS E DAS PLATAFORMAS}

Dado tratar-se de formas e depósitos com uma relação intrínseca com as posições do nível do mar, a metodologia mais óbvia poderá ser de tipo "geométrico". Isto é: as altitudes a que se desenvolvem as plataformas e os depósitos, poderiam, em princípio, ser utilizados na tentativa de os destrinçar. Porém, tudo isso deve ser avaliado com muito cuidado, já que existem indícios de que os depósitos sedimentares e as plataformas a eles associadas, foram afectados por deformações tectónicas.

Assim, aplicámos um modelo conceptual (ARAÚJO, 2001, Fig. 3) que nos tem permitido definir o escalonamento dos depósitos e plataformas existentes na área em estudo.
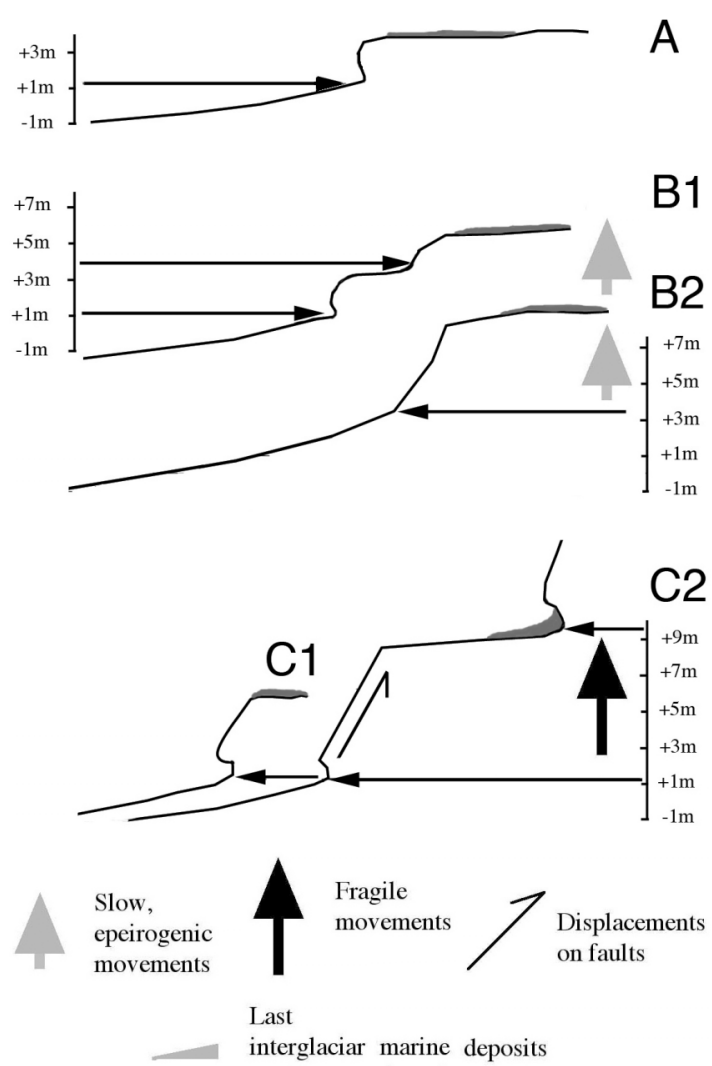

Fig. 3 - Proposta de modelo para as plataformas de erosão marinha da área estudada.

A. Plataforma fóssil com depósitos eemianos pouco acima da plataforma actual ( $\operatorname{cota}=3-4 \mathrm{~m})$. É o caso mais frequente. B1. Uma ligeira subida do continente pode alcandorar os depósitos eemianos a 5-6 m. Existe um pequeno entalhe basal (flandriano? Eemiano de um estádio posterior?) embutido na plataforma eemiana, a cotas de cerca de $3 \mathrm{~m}$. Casos das praias de Vila Chã e Labruge. B2. A plataforma actual parece ser poligénica e termina a uma altitude próxima dos 3,5m. Caso de Lavadores (Fig. 6 e 7). C1. O caso de S. Paio (Fig. 10): um depósito eemiano a 5-6 m. C2. O caso de S. Paio (morro do vértice geodésico). Um entalhe basal fóssil, com depósito marinho fóssil correlativo a 9-10 m, no alto de uma escarpa de direcção NNE-SSW.

Fig. 3 - A proposal for studied marine platforms development.

A. The Eemien platform ca 3-4m. Most frequent case. B1. Continental uplift: Eemien deposits ca 5-6 m. A tiny notch (Flandrian? Newer Eemien?) around $3 \mathrm{~m}$ (Vila Chã and Labruge beaches). B2. The actual marine platform goes till 3,5 $\mathrm{m}$ and seems to be polygenetic. C1. S. Paio beach: an Eemien marine deposit 5-6 m. C2: S. Paio, higher block: a fossil notch and a correlative marine deposit ca $9-10 \mathrm{~m}$.

A determinação precisa da altitude em relação ao nível médio actual do mar aplica-se, essencialmente, aos presumíveis registos do último 
interglaciar e tem permitido, por aproximações sucessivas, distingui-los dos depósitos e formas mais recentes (flandrianos e actuais).

Os depósitos presumivelmente do Eemiano que temos estudado são essencialmente marinhos. Ora, os depósitos marinhos podem encontrar-se a altitudes bastante superiores ao nível médio do mar (adiante designado como nível médio) que lhes deu origem. Com efeito, as areias marinhas podem estender-se até às bermas construídas pelo jacto da rebentação em períodos de tempestade e, por isso, podem ocorrer bastante acima do nível das marés altas equinociais.

Já as plataformas de erosão marinha de tipo A, segundo Sunamura (1992), apresentam uma relação bastante mais bem definida com o nível médio do mar. As plataformas de tipo A tendem a desenvolver-se entre o nível médio das marés baixas e o nível médio das marés altas.

No sítio Web da FCUL encontrámos dados referentes aos valores das marés para vários portos portugueses. No quadro 1 reproduzimos parcialmente o quadro referente aos portos de Viana, Aveiro e Faro no ano de 2008.

\section{Quadro 1}

\begin{tabular}{|l|c|c|c|c|c|}
\hline & $\begin{array}{c}\text { PM } \\
\text { max }\end{array}$ & $\begin{array}{c}\text { PM } \\
\text { med }\end{array}$ & NM & $\begin{array}{c}\text { BM } \\
\text { med }\end{array}$ & $\begin{array}{c}\text { BM } \\
\text { min }\end{array}$ \\
\hline $\begin{array}{l}\text { VIANA DO } \\
\text { CASTELO }\end{array}$ & 3,71 & 3,05 & 1,99 & 0,94 & 0,27 \\
\hline LEIXÕES & 3,76 & 3,07 & 2,00 & 0,93 & 0,28 \\
\hline AVEIRO & 3,41 & 2,87 & 1,98 & 1,1 & 0,58 \\
\hline FARO & 3,56 & 2,98 & 2,03 & 1,08 & 0,57 \\
\hline
\end{tabular}

PM max - Máxima Preia-mar do ano. PM med - Média de todas as Preias-mar. NM - Nível médio das marés. BM med - Média de todas as Baixas-mar. BM min - Mínima Baixa-mar do ano.

Os dados referentes a Leixões foram elaborados a partir dos elementos disponíveis no sítio Web do Instituto Hidrográfico para o mesmo ano.

Todos os valores se referem ao Zero Hidrográfico $(\mathrm{ZH})$ que corresponde a uma cota $-2 \mathrm{~m}$ relativamente ao nível médio, nos portos apresentados. Embora os valores médios das preiamares e baixa-mares sejam variáveis consoante os portos, pode dizer-se que são sempre muito próximos de $+3 \mathrm{~m}$ (i. e: $1 \mathrm{~m}$ acima do nível médio), para a média das preia-mares e $+1 \mathrm{~m}$ (i. e: $1 \mathrm{~m}$ abaixo do nível médio) para a média das baixamares.

A morfologia das plataformas de erosão marinha é variável de acordo com a posição do tramo em análise relativamente ao nível médio: abaixo do nível médio a plataforma é mais regular e tem menor declive; acima do nível médio a plataforma apresenta um maior declive (ANDRADE et al., 2002) e pode ligar-se a uma sapa (notch, encoche) que estabelece o contacto entre a plataforma de erosão marinha e a arriba que a limita para o interior.

Dada a importância da altitude das plataformas de erosão marinha para a identificação de eventuais movimentações tectónicas recentes, foi adquirido um equipamento GPS (Leica SR20), constituído por 2 receptores. Um dos receptores fica estacionário e um outro (rover) faz as medições de terreno. Este processo de trabalho permite uma definição bastante precisa da posição da estação de base, através do pós-processamento dos respectivos dados utilizando a estação de GPS de Vila Nova de Gaia. Depois de devidamente corrigida a posição da estação de base (em estacionamentos fixos e estáticos de cerca de 7 horas, que corresponde à duração da respectiva bateria), a sua posição é utilizada para processar os resultados obtidos em modo cinemático pelo rover.

Depois da correcção, feita através da estação de Gaia e do GPS de base, os dados de terreno, obtidos com o rover apresentaram precisões mínimas entre $\pm 14 \mathrm{~cm}$. Estes valores de erro foram obtidos por comparação da posição altimétrica de marcas de nivelamento do Instituto Geográfico Português (IGP), referentes ao datum de Cascais (1938), com os dados obtidos, para os mesmos pontos, com o GPS em modo estático, em estacionamentos de cerca de 20 minutos. Em Baptista (2006) encontrámos uma referência às ondulações do geóide que correspondem, na área do estuário do Douro a $2 \mathrm{~cm}$ por $\mathrm{km}$ de distância, o que poderá explicar uma boa parte das imprecisões encontradas. Significa isto que poderemos vir a obter uma precisão maior quando for possível introduzir, através do software, a ondulação do geóide na correcção dos dados obtidos.

Os dados de campo podem ser visualizados em mapas e fotografias aéreas, através de uma georeferenciação sumária efectuada pelo programa do GPS (Leica Geo Office, versão 3.0). Um exemplo dos resultados obtidos pode ser visualizado na figura 11.

\section{ESTUDO DA PLATAFORMA MARINHA ACTUAL}

Os dados respeitantes às altitudes das "sapas" actuais são variáveis, já que elas podem encontrarse em diferentes posições dentro da "rampa" que corresponde à plataforma de erosão marinha. Pode dizer-se que os valores máximos variam entre $0,8 \mathrm{~m}$ e 1,2 $\mathrm{m}$ acima do nível médio do mar, com uma média de exactamente $1 \mathrm{~m}$, o que significa que se desenvolvem, aproximadamente, até ao nível médio das marés altas, que se situa, grosso modo, cerca de $1 \mathrm{~m}$ acima do nível médio. 
Quanto ao limite exterior das plataformas actuais, é evidente que a sua medição está muito dependente da amplitude da maré em que se faz a medição e do facto de estarem ou não cobertas de sedimentos. Os dados recolhidos até ao momento permitem falar com segurança de cotas que vão, pelo menos, até $-1 \mathrm{~m}$.

Significa isto que, apesar de algum incerteza que decorre de erros imputáveis ao GPS e à ondulação do geóide, efectivamente, as plataformas de erosão marinha podem encontrar-se a cotas de $+1,2 \mathrm{~m} \mathrm{e}-1$ $\mathrm{m}$, o que significa que se desenvolvem aproximadamente, entre os níveis médios das marés altas e das marés baixas, como tinha sido postulado de início pelo modelo de Sunamura (1992).

Este facto permite-nos dizer que as sapas de altitude actual superior a $2 \mathrm{~m}$ acima do nível médio não poderão explicar-se por acção do actual nível relativo do mar.

\section{MODELO PARA A RELAÇÃo ENTRE AS PLATAFORMA ACTUAL, FLANDRIANA E EEMIANA}

Num anterior trabalho fez-se uma abordagem teórica sobre os diferentes aspectos que as plataformas de erosão marinha podem assumir aquando de variações eustáticas como aquelas que conhecemos nos últimos 125 mil anos, conjugadas ou não com desnivelamentos tectónicos de maior ou menor intensidade (ARAÚJO, 2001). A figura 3 resume aquilo que foi dito nessa altura e que, de um modo geral nos parece ainda válido. No fundo tudo se passa como na evolução de uma qualquer superfície geomorfológica quando sujeita a variações tectónicas ou do nível de base (FERREIRA, 1991). O resultado final é função da intensidade das referidas variações.

A largura da plataforma, por sua vez, vai depender essencialmente da resistência da rocha e do tempo de actuação das acções marinhas a um determinado nível. No caso dos granitos, as plataformas são sempre relativamente estreitas (a mais extensa, em Lavadores tem cerca de $50 \mathrm{~m}$ e deve esse facto a circunstâncias particularmente favoráveis sob o ponto de vista estrutural, como adiante será mostrado.

\section{ESTUdOS DE CASO}

\subsection{Praia da Aguda}

Num bordo continental que esteja a sofrer levantamento tectónico (CABRAL, 1995) as plataformas e os depósitos mais recentes aparecem, normalmente, embutidos nas plataformas e depósitos mais antigos.

Porém, nos casos em que essa subida relativa do continente não se verifica, o resultado pode ser diverso, como veremos.

Na praia da Aguda, o depósito atribuível ao Eemiano, que corresponde ao último interglaciar (está localmente coberto pela "formação arenopelítica de cobertura" (COSTA \& TEIXEIRA, 1957). Trata-se de uma formação solifluxiva, que cobre, indiferentemente da idade, muitas das formações da plataforma litoral e que foi estudada também por Nonn (1966) no litoral da Galiza, em Mougás, onde apresentou, no topo, idades correspondentes ao final do Würm. No litoral da região do Porto (Lavadores) segundo Araújo (1995) determinou-se uma idade superior a 44.370 anos para um depósito solifluxivo sobreposto a um depósito marinho presumivelmente eemiano. Quer isto dizer que existiram várias fases climáticas durante o último período frio que permitiram a génese de formações solifluxivas. Porém, tudo indica, pelas datações disponíveis, que elas correspondem a fases frias posteriores ao Eemiano. Por isso, a existência da formação de cobertura sobre um determinado depósito marinho, permite inferir que a sua idade será, no mínimo, eemiana (podendo, todavia, ser anterior).

No caso da praia da Aguda, o depósito atribuível ao Eemiano aparece a uma altitude que atinge como valor mínimo $+1,05 \mathrm{~m}$ (Fig. 4).

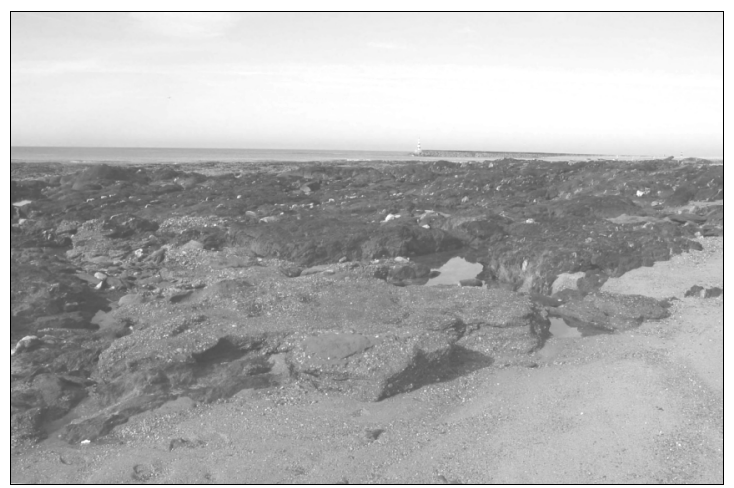

Fig. 4 - O depósito marinho eemiano, Praia da Aguda. Cota $=+1,05 \mathrm{~m}$.

Fig. 4 - Eemien marine deposit. Altitude $=+1,05 \mathrm{~m}$. Aguda beach.

Este mesmo depósito apresenta-se com cotas de 2,47 a uma distância de $293 \mathrm{~m}$ para SSE (Fig. 5). Pode, para já, pôr-se a hipótese de que o depósito eemiano aparece a altitudes diferenciadas porque está a fossilizar um paleo-relevo, anterior à transgressão eemiana. Esse paleo-relevo pode dever-se ao encaixe do ribeiro que desagua a meia distância entre as duas praias. Efectivamente, os 
afloramentos de cota mais baixa situam-se na sua proximidade (Fig. 5).

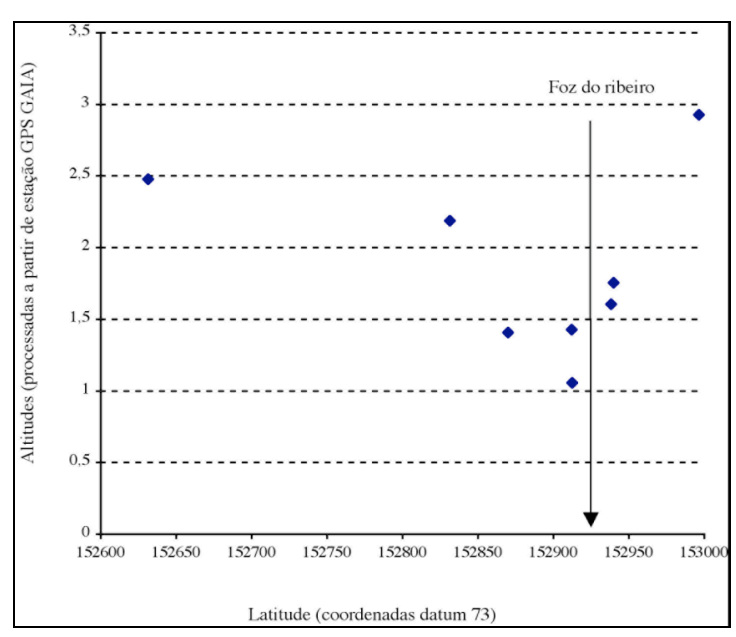

Fig. 5 - As diferentes altitudes do depósito eemiano na praia da Aguda.

Fig. 5 - Different altitudes for Eemian deposit, Aguda beach.

Na praia da Aguda, as plataformas eemiana e actual quase se confundem. Assim, a extensa plataforma que se observa nesta praia, com uma largura superior a $130 \mathrm{~m}$ em maré baixa, corresponde, em boa parte, a uma reutilização de uma plataforma eemiana, cuja idade pode comprovar-se pela sua fossilização parcial por arenitos e conglomerados ferruginosos (Fig. 4).

Sobre o conglomerado ferruginoso do Eemiano existe uma camada de argila escura (esverdeada a negra), cujo topo foi datado por termoluminescência de $8.67 \pm 0.78 \mathrm{ka}$ (ARAúJO et al., 2005). Estas argilas culminam a cotas de $+3,12$ m e evidenciam a existência de uma antiga lagoa durante o final do Würm e início do Holocénico.

Num momento posterior, sobre os materiais lagunares ter-se-ão depositado areias marinhas, correspondentes ao máximo da transgressão flandriana, sobrepostas, por sua vez, por areias eólicas. O depósito marinho flandriano sofreu também, tal como o depósito eemiano, um processo de cimentação por óxidos de ferro, devido ao facto de assentar sobre uma camada impermeável.

Estas areias ferruginosas, que se encontram a uma altitude de 3,2 m, vieram recobrir a sequência anteriormente descrita (depósito marinho eemiano e depósito lagunar fini-pleistocénico/holocénico) e contribuir para a conservação do conjunto, protegendo-o da erosão marinha.

Por isso, só a introdução de um forte factor de perturbação de origem antrópica (nomeadamente o quebra-mar da Aguda, concluído na Primavera de 2002), ao provocar uma erosão intensa a sul da praia da Aguda, veio permitir a observação desta sequência que reputamos do maior interesse para a compreensão das variações eustáticas e de uma possível tectónica recente nesta faixa costeira do Noroeste de Portugal. Com efeito, a existência de um segundo depósito marinho, também localmente ferruginizado, a cota superior à do depósito Eemiano, permite-nos extrair algumas conclusões relevantes:

- a existência de 2 depósitos marinhos, ambos ferruginizados, separados no tempo por cerca de $120 \mathrm{ka}$, faz-nos pensar que a identificação dos depósitos como eemianos deverá ser feita com algum cuidado, para evitar uma eventual confusão de depósitos flandrianos com os eemianos;

- neste local, o arranjo espacial dos depósitos está em desacordo com o escalonamento "normal" de terraços marinhos, em áreas com soerguimento tectónico. Com efeito, aqui temos, localmente, a situação inversa, com um depósito holocénico sobreposto a um depósito eemiano;

- referimos acima a hipótese de o antigo vale do curso de água que desagua entre as praias da Aguda e da Granja ter sido preenchido pelo conglomerado marinho do provável Eemiano. O facto de o depósito eemiano se encontrar, neste local, a cota inferior ao depósito flandriano, sugere esta hipótese, ou em alternativa, uma deformação tectónica local que poderia ter afectado, o depósito eemiano, rebaixando-o até às cotas mais baixas que foram encontradas em toda a área estudada, para depósitos deste tipo.

\subsection{Pequenas variações do Nível do Mar}

Teoricamente, sempre que há uma descida relativa do nível do mar, a antiga plataforma de erosão marinha fica suspensa acima do nível actual do mar. Por isso, o mar começa a formar uma nova plataforma, mais baixa, embutida na anterior.

No início deste processo forma-se uma frente de sapas que se desenvolve a partir do nível médio das marés baixas e até ao nível médio das marés altas. A erosão marinha irá explorar as fragilidades da rocha ao mesmo tempo que vai embutindo, numa superfície mais alta, uma plataforma mais baixa que se insinua de forma irregular, em regolfos, na plataforma mais antiga. A respectiva altimetria será adaptada às condições das marés a que nos referimos acima.

À medida que o processo erosivo avança, as sapas vão recuando e a sua cota torna-se progressivamente mais alta, de molde a permitir que a plataforma de erosão marinha que se desenvolve na sua base tenha um declive adequado às características do jacto de rebentação e à evacuação dos sedimentos resultantes do recuo da arriba. 
$\mathrm{O}$ contacto entre a nova plataforma e a plataforma mais antiga que a domina, poderá ser feito através de uma pequena arriba (Fig. 3A).

Este é o caso mais frequente e corresponde à situação em que uma provável plataforma eemiana se encontra soerguida relativamente à actual, acima do nível das marés altas. Essa plataforma pode ser identificada pela sua cobertura sedimentar (depósitos marinhos eemianos, eventualmente cobertos pela "formação areno-pelítica de cobertura"), erguendo-se acima da plataforma actual e separada dela por um degrau com 1-2 m de comando (Fig. 3A). Existirão, neste caso, duas plataformas escalonadas, uma mais alta de idade eemiana e uma actual, separada da anterior por uma pequena arriba, muitas vezes com um entalhe basal mais ou menos nítido. Esta sapa é frequente quando se trata de rochas resistentes do tipo dos granitos e gnaisses, como acontece nas praias da Foz do Douro e na praia de Vila Chã) (Fig. 6).

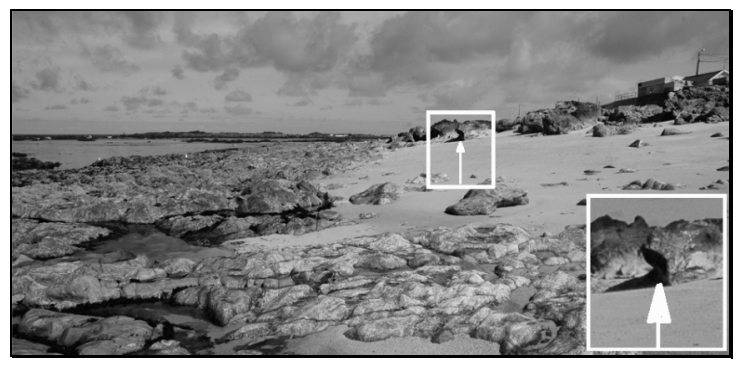

Fig. 6 - Aspecto da plataforma actual de Vila Chã, num momento de maré baixa viva. A seta indica a posição do entalhe $(0,9 \mathrm{~m}$ acima do nível médio). O topo do rochedo representa restos de uma plataforma mais antiga presumivelmente eemiana. A área delimitada com quadrado branco na foto está ampliada no canto inferior direito desta.

Fig. 6 - The marine platform at Vila Chã (low spring tide). The arrow indicates the position of the notch $(+0,9 \mathrm{~m}$ above mean sea level). The surface on the top of bedrock outcrops represents the remains of an old eemien platform. The area enclosed with white square in the photo is zoomed in the bottom right of this.

Como a variação relativa do nível do mar é de fraca amplitude não há lugar para a diferenciação de uma plataforma intermédia, eventualmente de idade flandriana.

\subsection{Movimentos ascencionais mais intensos: 0 caso da plataforma de Lavadores}

Uma vez que o nível do mar no máximo da transgressão flandriana estaria muito ligeiramente acima do nível actual, para que as variações do nível do mar que decorreram entre o máximo da transgressão eemiana e o período actual possam ficar registadas sob a forma de plataformas ou entalhes erosivos, parece-nos ser necessária uma certa subida do continente. Efectivamente, à medida que a intensidade dos movimentos ascencionais se acentua, a separação entre as plataformas de idade diferente vai-se tornando mais clara.

Se a diferença de altitude for pouco acentuada, ou se o substrato rochoso e as condições de exposição à ondulação forem propícias, o pequeno degrau que normalmente separa duas plataformas escalonadas, pode ser apagado pela erosão e formar-se uma rampa única, unindo a plataforma antiga e a recente. Nesse caso, a superfície resultante será de tipo poligénico. Apenas a altitude exagerada do limite interior da plataforma "actual" pode fazer suspeitar de que esta não corresponde inteiramente às condições do nível do mar na actualidade (Fig. 3B1).

$\mathrm{Na}$ praia de Lavadores (Fig. 7), existe uma extensa plataforma talhada nos granitos porfiróides, calco-alcalinos, que se desenvolve desde, pelo menos $-0,5 \mathrm{~m}$ e que passa suavemente, sem qualquer degrau digno de nota, até uma cota máxima de $+3,5 \mathrm{~m}$. A parte inferior e superior distinguem-se, apenas, pela maior intensidade dos processos abrasivos existentes na sua parte inferior.

Esta plataforma de erosão marinha é excepcionalmente extensa $(47 \mathrm{~m}$ de largura medidos com GPS) e regular. Tudo indica que a grande extensão e regularidade desta plataforma ficam a dever-se ao cruzamento de 2 fracturas aproximadamente perpendiculares (NW-SE e NE$\mathrm{SW}$, que terá facilitado o trabalho da erosão marinha e a ablação e arrasamento da "cunha" de granito situado entre essas duas fracturas. A referida plataforma está claramente embutida em retalhos aplanados, por vezes com restos de depósitos marinhos que aparecem a cotas bastante superiores $(6,9 \mathrm{~m}$ a $7,25 \mathrm{~m})$, (Fig. 8). Pelas características destes depósitos marinhos, por vezes cobertos pela "formação areno-pelítica de cobertura", podemos atribuir-lhe uma idade eemiana (último interglaciar). Assim sendo, a plataforma que se desenvolve entre $-0,5 \mathrm{~m}$ e $+3,5 \mathrm{~m}$, poderá corresponder a uma superfície poligénica prolongando a plataforma actual por uma outra, um pouco mais alta, correspondente, eventualmente, ao máximo da transgressão flandriana. $\mathrm{O}$ caso em apreço está apresentado de forma esquemática na figura 3B1.

Alternativamente, pode existir um entalhe intermédio, embutido na plataforma eemiana, claramente suspenso em relação ao entalhe actual.

É o caso do sector sul da praia de Vila Chã, junto ao porto de pesca (Fig. 9). Entre o topo da 
superfície culminante do rochedo $(\operatorname{cota}=3,85 \mathrm{~m}) \mathrm{e}$ um entalhe a 2,72 $\mathrm{m}$ existe um degrau abrupto. Por sua vez, esse entalhe, está claramente suspenso acima da sapa actual (altitude $=1,13 \mathrm{~m}$ ).

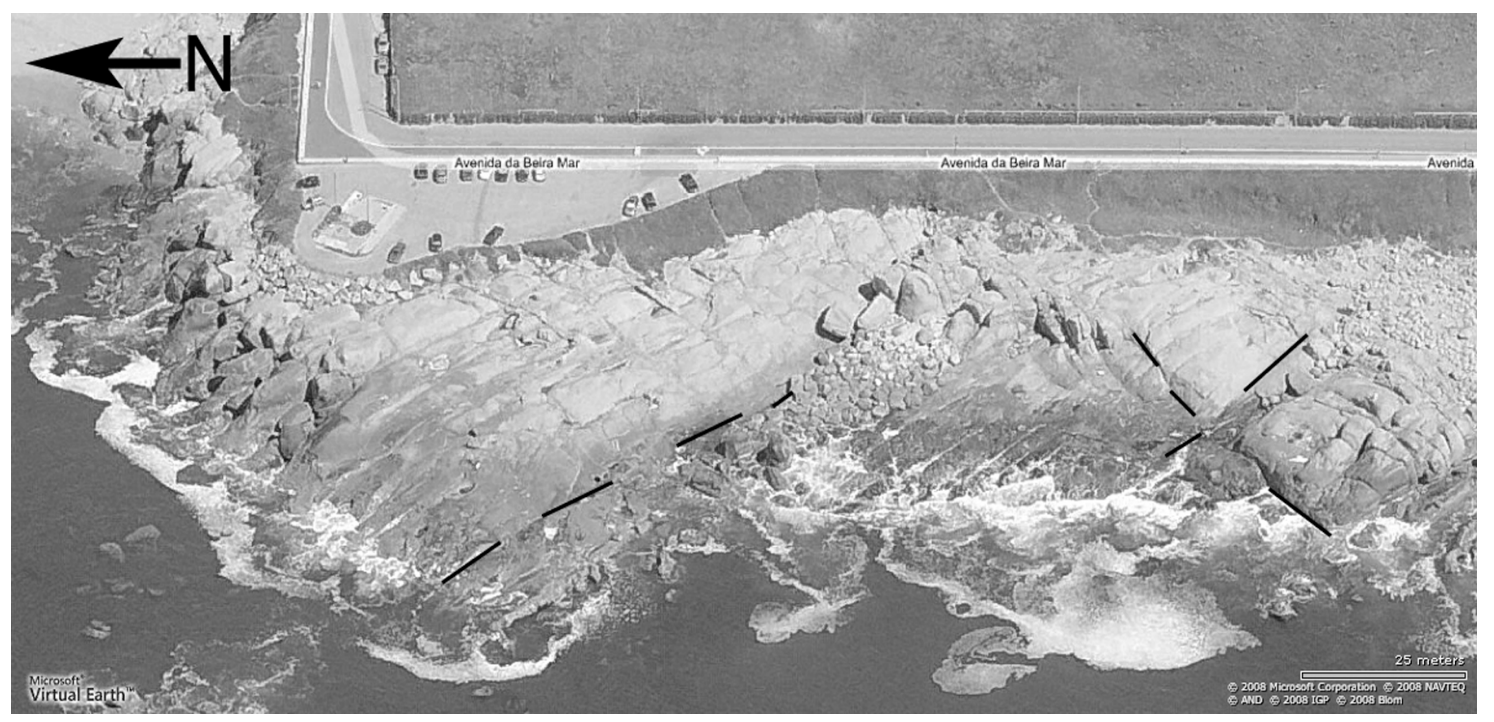

Fig. 7 - Vista de W, tipo bird's eye, da plataforma de erosão marinha de Lavadores, referida no texto, enquadrada pelas 2 fracturas NW-SE e NE-SW marcadas na fotografia.

Extraído do site Live maps http://maps.live.com/.

Fig. 7 - Lavadores marine platform, view from the West. The platform referred in the text lies between 2 important fractures: NWSE and NE-SW marked upon the photo.

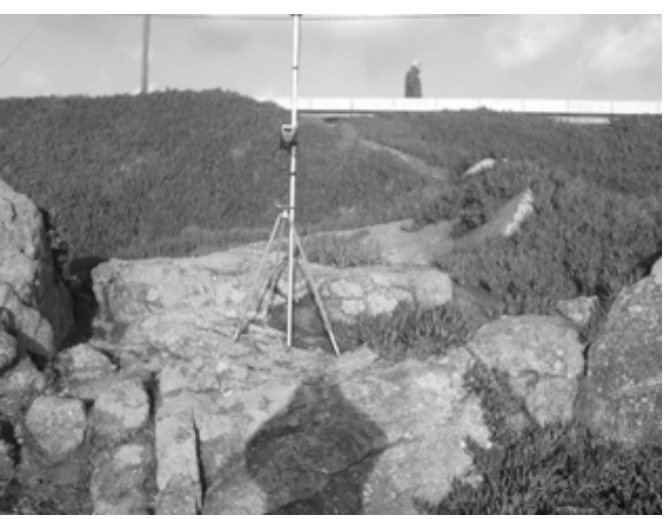

Fig. 8 - Plataforma eemiana e restos de depósitos nela existentes (Praia de Lavadores). Cota $=7,25 \mathrm{~m}$

Fig. 8 - Lavadores: eemien platform and eemien deposits remains. Altitude $=7,25 \mathrm{~m}$.

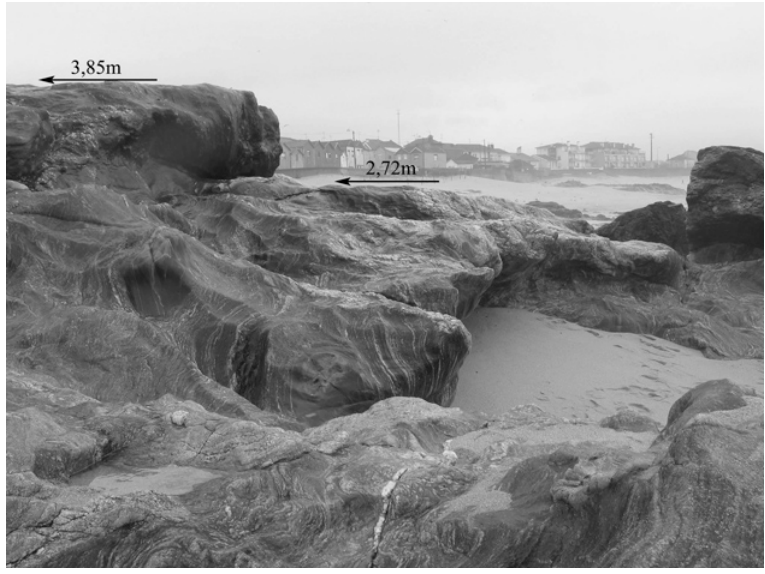

Fig. 9 - Plataforma eemiana $(\operatorname{cota}=3,85 \mathrm{~m})$ e entalhe possivelmente flandriano $(\operatorname{cota}=2,72 \mathrm{~m})$ na parte Sul da praia de Vila Chã. O entalhe actual está coberto por areias de praia. Num momento excepcional em que o encontrámos a descoberto foi possível definir uma cota aproximada de $1,13 \mathrm{~m}$.

Fig. 9 - Eemien platform $(+3,85 \mathrm{~m})$ and a possible flandrian notch $(+2,72 \mathrm{~m})$ at the southern part of Vila Chã beach. The actual notch is covered with beach sands. We could see it uncovered at a very rare occasion and its altitude was ca $1,13 \mathrm{~m}$. 


\subsection{Plataforma eemiana desnivelada tectonicamente: o caso de $S$. Paio}

$\mathrm{Na}$ figura 10 pode ver-se projectados num gráfico ortogonal, do tipo XY, todos os depósitos, provavelmente eemianos, encontrados na linha de costa estudada, que estiveram visíveis e foram localizados por GPS durante 2006 e no início de 2007. Uma vez que a latitude, em coordenadas Datum 73 definidas pelo GPS, está representada no eixo das abcissas, alguns depósitos parecem quase "sobrepostos". Trata-se, quer de um problema de escala (nesta figura estão representados pontos que ocorrem desde a foz do Rio Ave até à proximidade de Espinho, numa distância de $35,8 \mathrm{~km}$ ), quer do facto de a representação dos pontos através da sua latitude, numa linha de costa com uma direcção NNW-SSE, acabar por diminuir um pouco as distâncias, comprimindo-as.

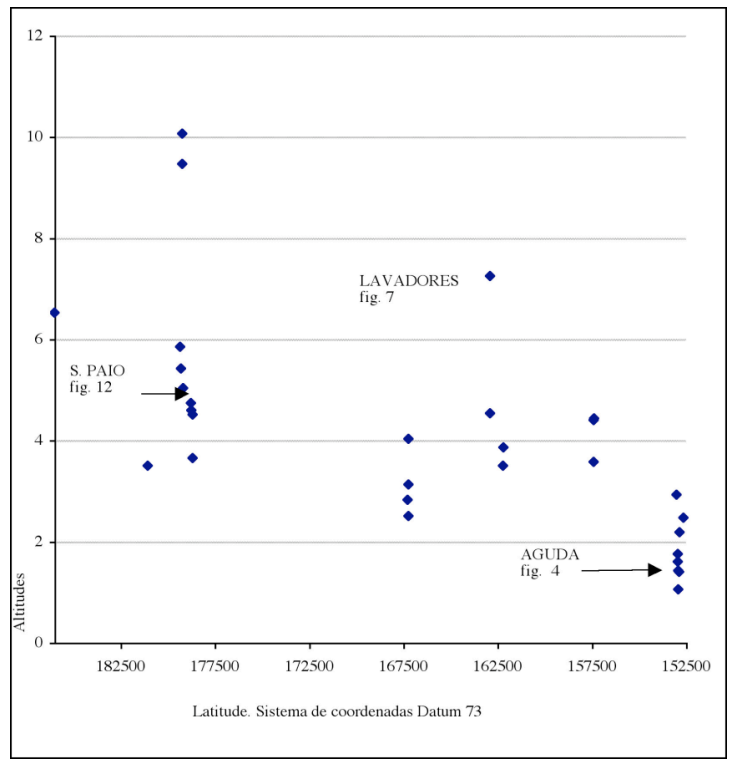

Fig. 10 - Posição dos afloramentos considerados eemianos ao longo da área estudada.

Fig. 10 -Eemien deposits altitude along the studied coastline.

Da análise da figura parece evidente o seguinte:

- os locais onde são visíveis estes depósitos concentram-se em alguns sítios bem definidos - isto é: não são visíveis em toda a linha de costa;

- em alguns locais encontram-se depósitos claramente soerguidos relativamente à cota "média" a que os depósitos eemianos se encontram nas proximidades;

- parece haver alguma tendência para os depósitos se encontrarem a maiores altitudes a norte da área estudada. Um dos locais em que se nota uma maior discrepância entre a posição "normal" dos depósitos eemianos e alguns afloramentos excepcionalmente altos, diz respeito à praia de Lavadores (Fig. 8). O outro caso muito nítido, diz respeito à praia de $\mathrm{S}$. Paio (Labruge, Vila do Conde) (ARAúJO, 1994). A fotografia aérea da figura 11 mostra, justamente, a área de S. Paio e a localização e cota dos diversos pontos implantados com o GPS. Vê-se claramente a orientação NNE-SSW das "arribas" deste troço litoral.

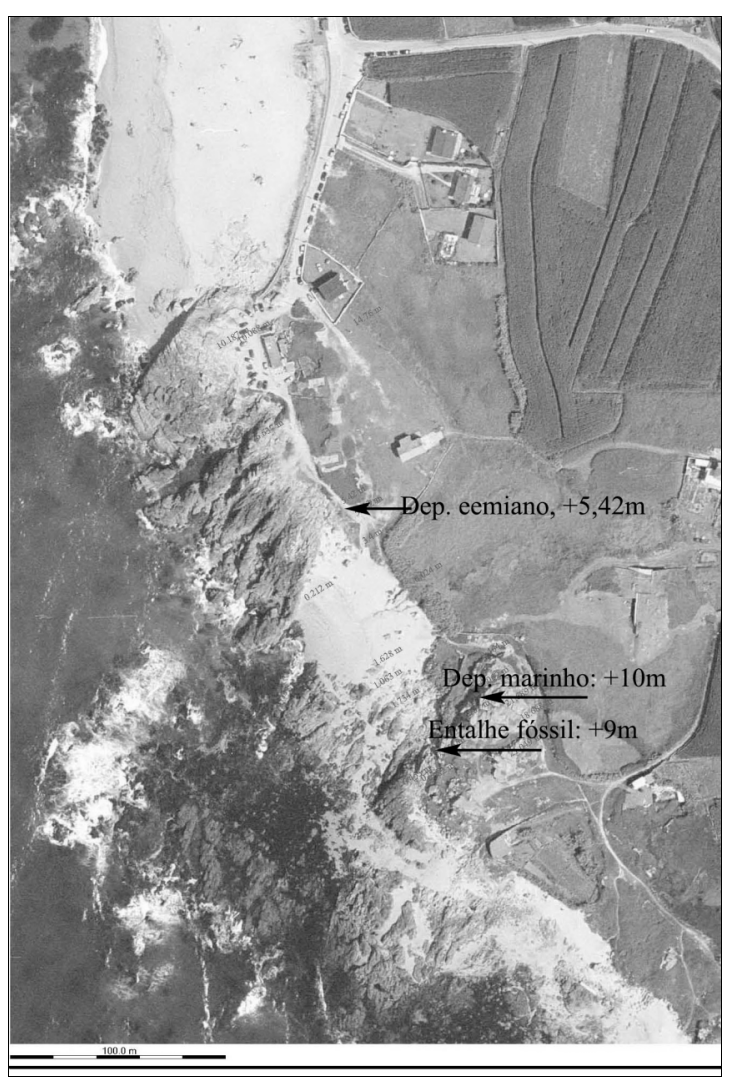

Fig. 11 - Fotografia aérea da área do S. Paio. Localização e cotas dos pontos definidos pelo GPS.

Fig. 11 - Aerial photo from S. Paio beach. Localization and altitudes of GPS points.

Entre o depósito que se encontra a $5,4 \mathrm{~m}$ e que serve de base a uma interessante sequência, provavelmente do início do Würm (Fig. 12) e o depósito situado a $10,1 \mathrm{~m}$, perto de uma espectacular sapa fóssil (ARAÚJO, 1994), a distância na horizontal é pequena (apenas $56,5 \mathrm{~m}$ ) e a diferença de cota $(4,7 \mathrm{~m})$ parece demasiado elevada se forem depósitos da mesma idade. Dispõe-se apenas de uma datação indirecta, por TL, do depósito eólico consolidado da sequência da figura 12, cujo resultado foi de $84+18 /-12$ ka BP (Nick Debenham, Quaternary TL Surveys, UK). 


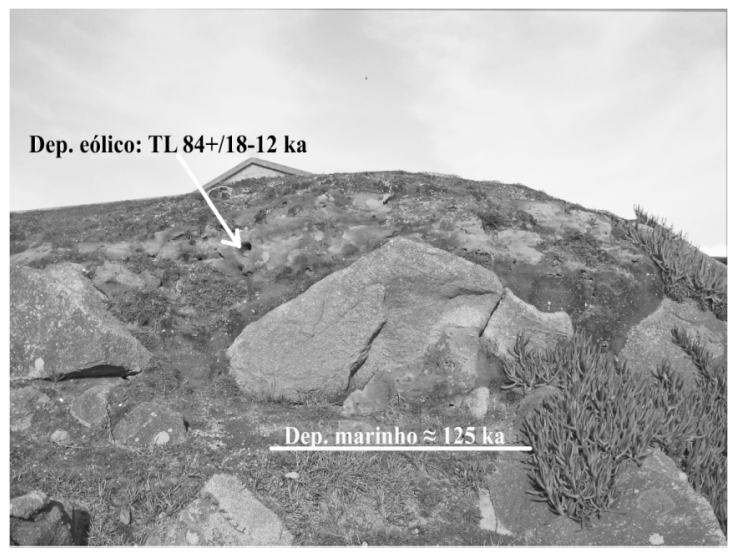

Fig. 12 - O corte do S. Paio. Depósito marinho da base (cota 5,4 m) e a formação eólica datada de 84+18-12 ka.

Fig. 12 - S. Paio outcrop. Eemien marine deposit (altitude $5,4 \mathrm{~m}$ ) and aeolian deposit 84+18-12 ky.

Segundo dados obtidos na região do Mar Vermelho (RoHLING et al., 2007), no estádio isotópico 5e, o nível do mar atingiu um nível aproximado de $+4( \pm 2) \mathrm{m}$, similar, de um modo geral, à altitude dos depósitos que estudámos. Seguidamente, os dados isotópicos sugerem uma descida acentuada do nível do mar, seguida de uma fase de aquecimento a que terá correspondido uma subida, posicionando-se o nível do mar a $-17 \mathrm{~m}$ (estádio isotópico $5 \mathrm{c}$ ). O processo de arrefecimento continuou a agravar-se e durante o estádio $5 \mathrm{a}$, a última fase anterior à glaciação do Würm, o nível do mar terá atingido cotas de $-30 \mathrm{~m}$ a $-40 \mathrm{~m}$, relativamente ao actual nível médio.

Necessariamente, o depósito marinho da base do corte de S. Paio (Fig. 12), deverá corresponder ao nível máximo do mar no estádio $5 \mathrm{e}$. Admitir que estes depósitos poderiam corresponder aos estádios $5 \mathrm{c}$ ou 5a implicaria uma subida tectónica incompatível com o carácter moderado dos movimentos que são conhecidos no litoral da região do Porto (cerca de $100 \mathrm{~m}$ em 2-3 milhões de anos (CABRAL, 1995).

Atendendo à diferença de altitude entre dois depósitos, presumivelmente da mesma idade, separados por uma escarpa com cerca de $9 \mathrm{~m}$ de comando, parece existir uma movimentação tectónica diferencial, posterior à formação dos depósitos eemianos. A figura 11 sugere que algumas arribas, rigidamente orientadas segundo a direcção NNE-SSW, mais não são do que escarpas de falha aparentemente recentes, apenas retocadas pelo mar na sua base.

O caso em apreço está representado de modo esquemático na figura $3 \mathrm{C}$.

Para podermos ter alguma segurança na atribuição cronológica dos vários episódios sedimentares registados na área de estudo, procedemos já à recolha de amostras para datação OSL, que já está em curso.

\section{CONCLUSÕES}

As dificuldades encontradas a propósito das tentativas de datação absoluta destes depósitos levaram-nos a recorrer a outras metodologias de trabalho, essencialmente a utilização de GPS, tentando, desta forma, através de uma análise fina dos dados de terreno, conseguir respostas consistentes para os problemas de correlação que desde há muito nos perseguem.

A existência de um soerguimento da margem continental parece-nos bastante clara no caso do S. Paio, em Labruge (Vila do Conde), onde as direcções herdadas da tectónica tardi-hercínica (RIBEIRO et al., 1979) parecem ter desnivelado depósitos do último interglaciar.

De uma forma menos clara, devido, em parte, à litologia (granito porfiróide com disjunção em blocos), também na área de Lavadores se pode inferir uma certa tendência para o levantamento, coincidente com um dos raros sectores de costa alta e rochosa existentes no litoral estudado.

No sentido Norte-Sul, em direcção a Espinho e à bacia Lusitânica, os afloramentos rochosos que testemunham antigos aplanamentos marinhos de idade presumivelmente eemiana, apresentam altitudes progressivamente mais baixas.

$\mathrm{Na}$ praia da Aguda, as formações do último interglaciar aparecem a cotas extraordinariamente baixas, o que permitiu que os depósitos flandrianos, (geralmente mais baixos do que os eemianos), se viessem sobrepor àqueles, o que sugere que este sector costeiro estará a sofrer subsidência, ao contrário do comportamento regional, que é de soerguimento tectónico.

A compreensão das variações relativas do nível do mar na costa noroeste de Portugal, é um objectivo ambicioso já que o objecto de estudo é variado e complexo. A imagem que vamos construindo poderá funcionar como um puzzle que se irá resolvendo por ajustes sucessivos e cuja reconstituição vai requerer metodologias novas ou a aplicação criativa de metodologias pré-existentes.

Temos consciência da urgência destes estudos a erosão que a maior parte da costa Norte de Portugal está a sofrer pode acabar, a curto prazo, com a maioria destes testemunhos de um passado longínquo, impedindo o seu estudo futuro. 
Depósitos do Pleistocénico superior e do Holocénico na plataforma litoral da região do Porto: a morfologia das plataformas de erosão marinha e a tectónica recente

\section{Agradecimentos}

O financiamento necessário à realização deste trabalho foi assegurado, em parte, pelo projecto POCTI/CTA/38659/2001 e pelo GEDES (Gabinete de estudos de desenvolvimento (sediado na FLUP). Agradecemos a Nick Debenham (Quaternary TL Surveys) o profissionalismo e a rapidez com que nos forneceu os resultados das datações por TL. Aos Professores Pedro Proença Cunha (Universidade de Coimbra) e António Martins (Universidade de Évora) agradecemos todo o apoio dado a propósito das datações TL efectuadas e os esclarecimentos a propósito das datações OSL. Ao Professor Nils-Axel Mörner agradecemos as frutuosas discussões no terreno que nos fizeram precisar e reajustar a problemática da nossa área de trabalho. À Professora Ana Ramos Pereira (Universidade de Lisboa) agradecemos a leitura crítica do texto e as sugestões que permitiram o seu aprofundamento e melhoria. À Câmara Municipal de Vila do Conde agradecemos a possibilidade de utilização das fotografias aéreas do litoral do concelho.

\section{BIBLIOGRAFIA}

Andrade, C.; Marques, F.; Freitas, M.C.; Cardoso, R. \& MAduREIRA, P. (2002). Shore Platform Downwearing And Cliff Retreat In Portuguese West Coast, Littoral 2002 Proceedings, Vol. 2, Porto, Eurocoast-Portugal, FEUP, pp. 423-432.

ARAÚJO, M.A. (1991). Evolução geomorfológica da plataforma litoral da região do Porto, Tese de doutoramento, Universidade do Porto.

ARAúJo, M.A. (1994). Protection and Conservation of Sampaio Area (Labruge, Vila do Conde, North of Portugal), in "Littoral/94" proceedings, Associação EurocoastPortugal, IHRH (Instituto de Hidráulica e Recursos Hídricos da Univ. do Porto) e ICN (Instituto de Conservação da Natureza), Vol. II, pp. 865-877.

ARAúso, M.A. (1995). Os fácies dos depósitos würmianos e holocénicos e as variações climáticas correlativas na plataforma litoral da região do Porto, Actas do VI Colóquio Ibérico de Geografia, Publicações da Universidade do Porto, pp. 783-793.

ARAÚJO, M.A. (1997). A plataforma litoral da região do Porto: Dados adquiridos e perplexidades. Estudos do Quaternário, 1, pp. 3-12.

ARAúJO, M.A. (2000). Depósitos de fácies continental e marinho na plataforma litoral da região do Porto: importância da tectónica na sua organização espacial, Ciências da Terra (UNL), 14, pp. 111-122.

ARAÚJO, M.A. (2001). Marine platforms from Oporto area (NW Portugal): Tectonics versus eustasy, Actas da $\mathrm{V}$ Reunião do Quaternário Ibérico, GTPEQ e AEQUA, Lisboa, pp. 178-181.

AraúJo, M.A.; Gomes, A.; Chaminé, H.I.; FonSECA, P.E. Gama Pereira, L.C. \& Pinto De Jesus, A. (2003). Geomorfologia e geologia regional do sector de PortoEspinho (W de Portugal): implicações morfoestruturais na cobertura sedimentar cenozóica, Cad. Lab. Xeol. Laxe, 28, pp. 79-105.
AraúJo, M.A., Rodrigues, S. \& Gomes, A. (2005). Eemien and Flandrian deposits on Porto (northern Portugal) littoral platform: the contribution of archaeology, Apresentação oral na VI Conferência internacional de Geomorfologia em Zaragoza, Livro de Resumos, p. 231.

BAPTISTA, P.E.R.B., (2006). O Sistema de Posicionamento Global Aplicado ao Estudo de Litorais Arenosos, Tese de doutoramento, Universidade de Aveiro, Departamento de Geociências.

CABral, J.M.L.C. \& RiBeIRO, A. (1989). Carta Neotectónica de Portugal (escala 1:1000000). Serv. Geol. Portugal, Lisboa.

CABRAL, J.M.L.C. (1995). Neotectónica de Portugal Continental, Memórias do Instituto Geológico e Mineiro, 31 .

CHAMINÉ, H.I. (2000). Estratigrafia e estrutura da faixa metamórfica de Espinho-Albergaria-a-Velha (Zona de Ossa-Morena): implicações geodinâmicas, Tese de doutoramento, Universidade do Porto.

Chaminé, H.I.; GAMA PEREIRA, L.C.; FONSECA, P.E.; Noronha, F. \& Lemos DE SOUSA, M.J. (2003). Tectonoestratigrafia da faixa de cisalhamento de PortoAlbergaria-a-Velha-Coimbra-Tomar, entre as Zonas Centro-Ibérica e de Ossa-Morena (Maciço Ibérico, W de Portugal), Cad. Lab. Xeol. Laxe, 28, pp. 37-78.

Chaminé H.I., Gomes A., TeIXeIRA J., Fonseca P.E., PINTO DE Jesus A., Gama Pereira L.C., SoAres de Andrade A.A., Fernandes J.P., MoçO L.P., Flores D., ARAúJo M.A. \& RochA F.T. (2004). Geologia, geomorfologia e estratigrafia dos domínios estruturais de Carvoeiro-Caldas de S. Jorge e de Arrancada do Vouga-Águeda (faixa de cisalhamento de Porto-Tomar, NW de Portugal): implicações paleogeográficas, Cad. Labor. Xeol. Laxe, 29, pp. 299-330.

Costa, J. C. \& TeIXeIRA, C. (1957). Carta Geológica de Portugal na escala de 1:50000, noticia explicativa da folha 9-C (PORTO), Serv. Geol. de Portugal, Lisboa.

FACULDADE DE CIÊNCIAS DA UNIVERSIDADE DE LISBOA http://webpages.fc.ul.pt/ cmantunes/hidrografia/hidro_ma res.html

FERreirA, A.B. (1991). Neotectonics in Northern Portugal - a Geomorphological approach, Z. Geomorph. N. F. Supl., Bd. 82, pp. 73-85.

INSTITUTO HIDROGRÁFICO http://www.hidrografico.pt/previsao-mares.php

MARTINS, A.A. \& CUNHA, P.P. (2006a). Vantagens e limitações da luminescência opticamente estimulada na datação de terraços do rio Tejo, sua importância na determinação da taxa de incisão fluvial, In: J. Mirão \& A. Balbino (eds.), VII Congresso Nacional de Geologia, Livro de Resumos, Évora, Vol. II, pp. 683-686.

MARtins, A.A. \& CUNHA, P.P. (2006b). Possibilidades de aplicação da luminescência opticamente estimulada (osl) na datação de sedimentos do rio Tejo. Tagus Floods '06 Workshop, 19-21 July, Lisbon, Portugal, Project POCTI/CTA/39427/2001, pp. 72-75.

NonN, H. (1966). Les régions cotières de Galice (Espagne) Etude géomorphologique, Pub. Fac. Letras Univ. Estrasburgo.

NORONHA, F. \& LeterRier, J. (2000). Complexo metamórfico da Foz do Douro (Porto). Geoquímica e geocronologia, Rev. Real Acad. Galega Ciencias, 19, pp. 21-42.

Pereira, D.I.; Alves, M.I.C.; Araújo, M.A. \& ProençA CunHA, P. (2000). Estratigrafia e interpretação paleogeográfica do Cenozóico continental do Norte de Portugal, Ciências da Terra (UNL), 14, pp. 73-84. 
Ribeiro, A. (1984). Néotectonique du Portugal, Livro de Homenagem a Orlando Ribeiro, Centro de Estudos Geográficos, Lisboa, pp. 173-182.

RiBeIRo, A. (2002). Soft plate and impact tectonics. SpringerVerlag, Berlin, Heidelberg.

RIBEIRO, A.; ANTUNES, M.T.; FERREIRA, M.P.; ROCHA, R.B.; SOARES, A.F.; ZBYSZEWSKI, G.; ALMEIDA, F.M.; CARVALHO, D. \& MONTEIRO, J. H. (1979). Introduction à la Géologie Générale du Portugal, Serviços Geológicos de Portugal. Lisboa.
Rohling, E. J.; Grant, K.; Hemleben, Ch.; Siddall M.; HOOGAKKER, B.A.A.; BOLSHAW, M. \& KUCERA M. (2007). High rates of sea-level rise during the last interglacial period, Nature Geoscience, doi:10.1038/ngeo.2007.28.

SUnAmURA, T. (1992). Geomorphology of Rocky Coasts, John Wiley \& Sons, Chichester.

TeIXeIRA, C. (1968). Aspectos geológicos da orla litoral do Porto e de V. N. de Gaia, Naturalia, pp. 13-29.

WALLINGA, J. (2002). Optically stimulated luminescence dating of fluvial deposits: a review, Boreas, 31, pp. 303-322. 